\title{
Empirical antibiotics use in soft tissue infections
}

\author{
Rodger Shortt MD ${ }^{1}$, Achilleas Thoma MD MSc FRCSC FACS $1,2,3$
}

\author{
R Shortt, A Thoma. Empirical antibiotics use in soft tissue \\ infections. Can J Plast Surg 2008;16(4):201-204.
}

PURPOSE: Various antibiotics are available to treat soft-tissue infections. However, it is unclear if the empirical antibiotic is always appropriate or the most economical.

OBJECTIVE: To determine the percentage of empirically treated wounds susceptible to the antibiotic therapy prescribed, and to determine the percentage of wounds treated with the most economical antibiotic therapy.

METHODS: A retrospective chart review was performed on all charts with a diagnosis of 'soft-tissue infection' between January 1, 2005, and June 30, 2005, at St Joseph's Hospital, Hamilton, Ontario. Eligible charts were identified using the medical diagnosis coding system. The following diagnoses (including subheadings) were included: cellulitis, lymphangitis, abscess, carbuncle or furuncle. The following was extracted: patient demographics; soft-tissue diagnosis; name, dose and duration of antibiotics used; culture results; and Gram-stain results. A comparison between the empirical antibiotic prescribed and the microbiology result was made. An assessment was performed on the cost of the initial empirical antibiotic treatment compared with less-expensive effective alternatives.

RESULTS: For soft-tissue infections with positive culture growth, empirical antibiotic treatment was appropriate in all abscess cases, $50 \%$ of ulcer cases and $83 \%$ of cellulitis cases. For cellulitis patients receiving a single empirical antibiotic, it was appropriate in $89 \%$ of cases. Only $42 \%$ of culture-positive patients were treated with the most economical regimen, multiple antibiotics being the most common fault.

CONCLUSIONS: To be most economical, a single empirical antibiotic should be used to treat cellulitis. Culture results should be used to guide any antibiotic changes.

Key Words: Antibiotics; Economics; Empirical; Soft-tissue infection

\section{Le recours à l'antibiothérapie empirique dans les infections des tissus mous}

BUT : Il existe plusieurs antibiotiques différents pour traiter les infections des tissus mous. Toutefois, on ignore si l'antibiothérapie empirique est toujours appropriée ou si elle est la plus économique.

OBJECTIF : Déterminer le pourcentage des infections des tissus mous traitées empiriquement qui sont sensibles à l'antibiothérapie prescrite; et déterminer le pourcentage des lésions qui sont traitées au moyen de l'antibiothérapie la plus économique.

MÉTHODES : Les auteurs ont procédé à une analyse rétrospective de tous les dossiers où figurait un diagnostic d'infection des tissus mous entre le $1^{\text {er }}$ janvier et le 30 juin 2005, à l'Hôpital St. Joseph de Hamilton, en Ontario. Ils ont identifié les dossiers admissibles à l'aide du système de codes diagnostiques et ont inclus les diagnostics suivants (y compris les sous-diagnostics) : cellulite, lymphangite, abcès, anthrax ou furoncle. Les données extraites comprenaient : les caractéristiques démographiques des patients, le diagnostic d'infection des tissus mous, le nom, la dose et la durée de l'antibiothérapie utilisée, les résultats des cultures et des antibiogrammes. Les auteurs ont ensuite comparé l'antibiothérapie prescrite et les résultats microbiologiques. Ils ont évalué le coût de l'antibiothérapie empirique initiale comparativement à des solutions de rechange efficaces moins coûteuses.

RÉSULTATS : Pour les infections des tissus mous dont les résultats de culture étaient positifs, l'antibiothérapie empirique a été jugée appropriée dans tous les cas d'abcès, dans $50 \%$ des cas d'ulcères et dans $83 \%$ des cas de cellulite. Chez les patients souffrant de cellulite ayant reçu un seul type d'antibiothérapie, cette dernière a été jugée appropriée dans $89 \%$ des cas. Seulement $42 \%$ des patients dont les résultats de culture étaient positifs ont été traités au moyen du schéma le plus économique, l'emploi de multiples antibiotiques, représentant l'erreur la plus répandue.

CONCLUSIONS : Pour le traitement de la cellulite, il est préférable d'utiliser l'antibiotique empirique le plus économique en monothérapie. Il faut orienter tout changement d'antibiothérapie en fonction des résultats des cultures.

not known how often the most economical choice has been made. Because in most jurisdictions health care resources are constantly shrinking, it behooves us all to exercise caution how we spend these limited resources.

The primary question of the present study was to determine what percentage of empirically treated soft tissue infections was found to be susceptible to the prescribed antibiotic (Abx) therapy. The secondary question was to determine what percentage of appropriately treated soft tissue infections were treated by the most economical Abx therapy.

\section{METHODS}

After obtaining institutional Research Ethics Board approval, a retrospective chart review was performed on all patients admitted to St Joseph's Hospital, Hamilton, Ontario, between January 1, 2005, and June 30, 2005, diagnosed with a 'soft-tissue bacteria. However, it is not clear how often this empirical choice is actually correct. Furthermore, even if it is correct, it is

${ }^{1}$ Division of Plastic Surgery, Department of Surgery; ${ }^{2}$ Department of Clinical Epidemiology and Biostatistics; ${ }^{3}$ Surgical Outcomes Research Centre (SOURCE), McMaster University, Hamilton, Ontario

Correspondence: Dr Achilleas Thoma, McMaster University, St Joseph's Healthcare, 206 James Street South, Suite 101, Hamilton, Ontario

L8P 3A9. Telephone 905-523-0019, fax 905-523-0229, e-mail athoma@mcmaster.ca 


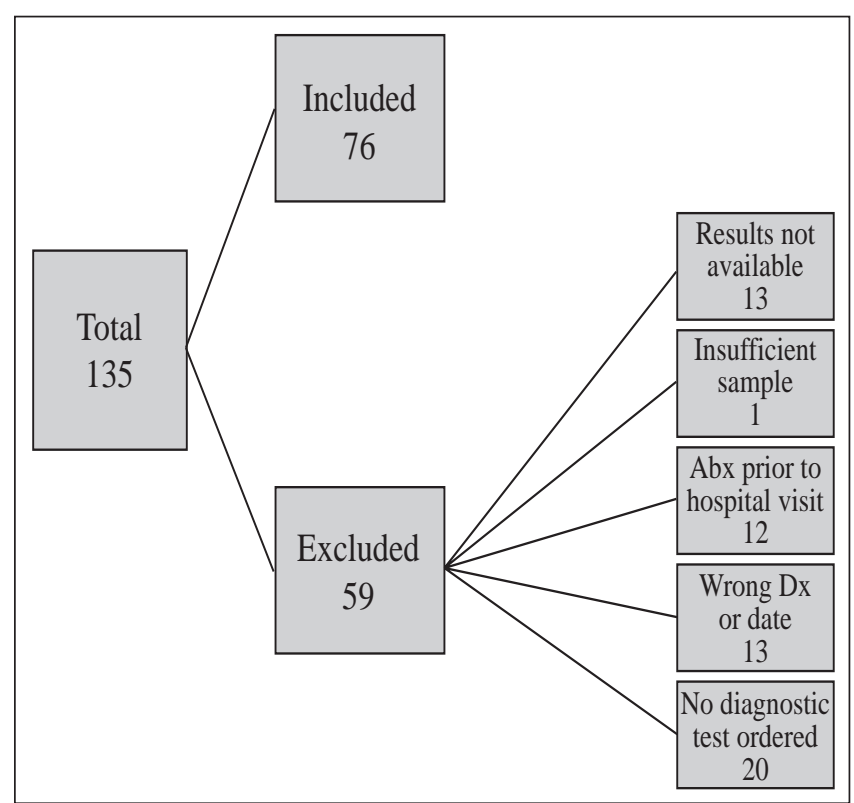

Figure 1) Flowchart depicting the article selection process, including reasons for article exclusion. Abx Antibiotic, Dx Diagnosis

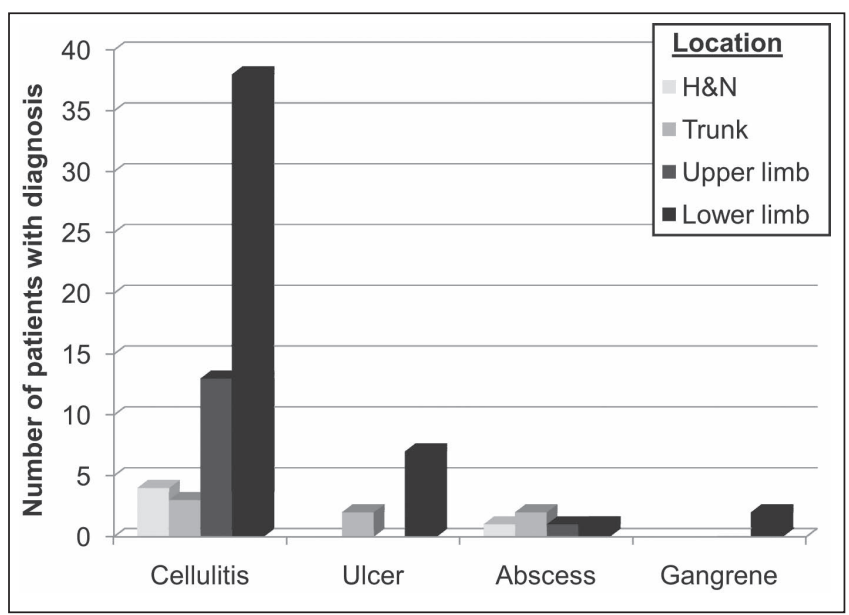

Figure 2) Distribution of soft-tissue infections by diagnosis and body site. There was also a single case of varicella zoster, shingles and vasculitis. HENN Head and neck

infection'. Patients were identified using the International Classification of Disease (8) codes for cellulitis, lymphangitis, abscess, carbuncle or furuncle (including all subheadings). Pertinent data extracted from each chart included patient demographics, soft tissue diagnosis, antibiotic information (including dosage, duration, date of initiation and alterations to regimen), Gram stain, and culture and sensitivity (C\&S) results from swab, tissue or blood.

To be included, patients had to have been diagnosed with a soft-tissue infection during the specified time period.

Patients were excluded if antibiotics were started before their hospital visit; if a Gram stain or C\&S was not performed; if antibiotic therapy was started after the Gram stain or C\&S results were available; or if there was inadequate information in the chart to adequately assess the course of the patient's illness.
TABLE 1

Types of antibiotics used, their frequency of use and average daily hospital cost

\begin{tabular}{lcc}
\hline Antibiotic & $\begin{array}{c}\text { Frequency } \\
\text { of use (\%) }\end{array}$ & $\begin{array}{c}\text { Average } \\
\text { daily cost (\$) }\end{array}$ \\
\hline Cefazolin (IV) & 47 & 8.97 \\
Ciprofloxacin (IV) & 21 & 71.47 \\
Cefotaxime (IV) & 20 & 27.07 \\
Clindamycin (IV) & 16 & 4.16 \\
Cloxacillin (IV) & 11 & 9.10 \\
Metronidazole (IV) & 8 & 4.08 \\
Ciprofloxacin (PO) & 7 & 1.72 \\
Clindamycin (PO) & 7 & 4.16 \\
Metronidazole (PO) & 4 & 0.10 \\
Vancomycin (IV) & 4 & 27.83 \\
Cephelexin (PO) & 4 & 0.83 \\
Moxifloxacin (PO) & 4 & 10.00 \\
Piperacillin-tazobactam (IV) & 3 & 72.16 \\
Penicillin G (IV) & 1 & 21.79 \\
Ampicillin (IV) & 1 & 17.63 \\
Cloxacillin (PO) & 1 & 0.41 \\
Levofloxacin (IV) & 1 & 39.47 \\
\hline V Intravenous; PO BV mouth & & \\
\hline
\end{tabular}

IV Intravenous; PO By mouth

Empirical antibiotic appropriateness was ascertained by comparing the empirical antibiotic with the results of the microbiology resistance and sensitivity report.

Determination of whether a less expensive, albeit still effective, antibiotic could have been substituted was based on average daily hospital pharmacy costs.

Statistical analysis was performed where applicable using the $\chi^{2}$ test. Statistical significance was set at $\mathrm{P}<0.05$. Other results were reported as percentages.

\section{RESULTS}

During the six-month time period, 135 patients were admitted with soft-tissue infections. Of these, 76 were included in the present study. Reasons for exclusion are shown in Figure 1. The most common soft-tissue infection was cellulitis, followed by infected ulcers, abscess and gangrene (Figure 2). Individual cases of lymphangitis, herpes zoster and vasculitis were also included. Of the 76 patients included in the study, only 33 showed bacterial growth on their Gram stain and C\&S studies, which could be used to assess the efficacy of the empirical antibiotic.

For the 76 patients, 17 different antibiotics were used (Table 1). Only $58 \%$ of patients were treated with a single empirical antibiotic, and the remainder received either double or triple empirical antibiotic coverage. Additionally, two different antivirals (famciclovir and acyclovir) were used for the treatment of suspected herpes zoster cases.

Antibiotic revisions were made in $78 \%$ of patients. Nearly one-third $(28 \%)$ of these revisions were made based on the C\&S result. The remainder were changed for a variety of reasons, the most common being a transition from intravenous to oral therapy.

Initial antibiotic decisions were made by the resident house staff in 43 of 76 cases (57\%) and by consulting physicians in 21 of $76(28 \%)$. It was unclear in the remainder of cases. For the cases in which the $C \& S$ grew bacteria, residents were 
found to have prescribed at least one appropriate antibiotic in 16 of 19 cases (84\%) while staff did so in six of eight $(75 \%)$ cases $(\mathrm{P}=0.32)$. Multiple antibiotics were used in 22 of 42 cases $(52 \%)$ by residents and in 13 of 21 cases $(62 \%)$ by staff $(\mathrm{P}=0.54)$. Neither of these were statistically significant differences.

Cellulitis represented the most common soft-tissue infection (Figure 3). Twenty-three of the 57 patients had positive blood culture results which were used for antibiotic assessment. Of those, 19 of the 23 (83\%) were treated with at least one antibiotic to which the bacteria were determined to be sensitive. When cost analysis was performed, only 32\% of these were treated with the most economical regimen. For the majority of patients that received an unnecessarily expensive antibiotic regimen (nine of 13), the reason for the excess cost was multiple antibiotic use. The remaining cases represented the use of expensive antibiotics when a less expensive option would have sufficed. An example is the use of piperacillintazobactam instead of cefazolin, with average daily costs of $\$ 72.16$ and $\$ 8.97$, respectively. When patients with cellulitis who received a single empirical antibiotic were analyzed, eight of the nine $(89 \%)$ received treatment to which the bacteria were sensitive.

Three of the five abscess cases had bacterial growth on the C\&S. All were treated with an appropriate antibiotic regimen, which was also found to be the most economical therapy. Four of the nine infected ulcer cases had bacterial growth on the C\&S. Two of these four were treated appropriately; only one of which received the most economical therapy. Two patients had gangrene, one of which was treated appropriately; however, not with an economical regimen.

\section{DISCUSSION}

The present study reviewed patients admitted to a tertiary care teaching centre over a six-month period with soft-tissue infections requiring antibiotic treatment. Admitted patients were chosen for the study because it was possible to follow their course in hospital through daily progress reports, whereas patients treated in the emergency department were not routinely seen in follow-up. Therefore, we could not determine the success or failure of their treatment. Over a six-month period, cellulitis was the most common soft-tissue infection admitted to hospital. This was followed by infected ulcers, abscesses and gangrene.

The present study supports previous findings that empirical antibiotic use is extremely variable (3). In a six-month period, 17 different antibiotics and two antiviral medications were used. The reason for such a high number of empirical antibiotics is not clear. Lack of a specific hospital treatment algorithm, lack of knowledge regarding local bacteria prevalence and personal preferences all likely contribute to the explaining the variety.

The number of patients treated with double and triple therapy was also quite high. This finding has also been reported in the literature (3). This was the most common reason that empirical therapy was less economical than ideal. However, it is unclear why double and triple coverage was used so frequently. Soft-tissue infections, which can result from a myriad of bacteria, are well known to result from a few common bacterial species, such as Staphylococcus and Streptococcus (1-4).

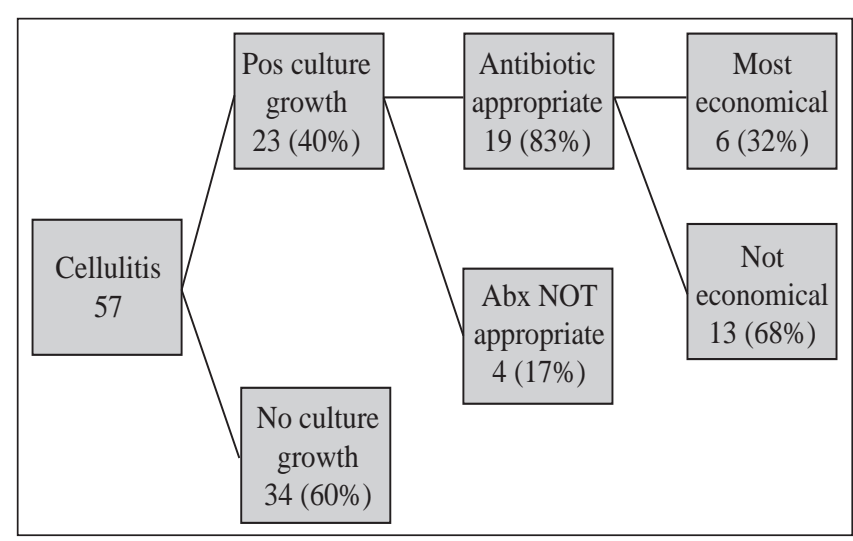

Figure 3) Appropriateness of cellulitis management; 83\% treated with an appropriate antibiotic. Only one-third were treated with the most economical regimen. Abx Antibiotic; Pos Positive

The fact that a single antibiotic treatment was not generally used may be due to disease severity, because patients admitted are presumably sicker than those discharged from the emergency room. This is supported by results from a separate unpublished study done by the present authors looking at antibiotic use in the emergency department. In that setting, only eight of $174(4.6 \%)$ patients received multiple antibiotics. A second possible explanation was that the present review occurred at an academic teaching hospital. The majority of initial medical decisions were made by house staff. It is plausible that inexperience could lead to broader empirical treatment protocols. However, our results suggested this was not the case. Admittedly, the study lacked power to confirm this.

Due to the limited number of patients it is difficult to perform meaningful statistics on much of our data. As such, this is a descriptive paper illustrating our findings. However, because the number of cellulitis patients was fairly high, we could abstract some meaningful trends. The first of these is that most patients received an antibiotic that was appropriate for their microbiology. Seventy-eight per cent of all patients with cellulitis received at least one appropriate antibiotic; the most common against Staphylococcus aureus and Streptococcus species, particularly groups A, B and G. When a subgroup analysis of patients who received a single antibiotic was performed, it was found that $89 \%$ of these patients received an appropriate antibiotic. The second trend is that excessively expensive antibiotic therapies were provided, usually as a result of multiple antibiotics that were not warranted based on the bacteria grown in culture. The other common reason was the use of unnecessarily expensive antibiotics. An example was the use of piperacillin-tazobactam in place of cefazolin (average daily cost $\$ 72.16$ versus $\$ 8.97$, respectively). Another cause of excess expenditure was the prolonged use of the intravenous form of drugs with similar bioavailability in oral forms, such as ciprofloxacin ( $\$ 71.47$ versus $\$ 1.72$, respectively). In light of this, we support a previous paper's recommendation that a single antibiotic agent targeted against the most common bacteria be used in the hospital population (Staphylococcus and Streptococcus) (1). Any changes to antibiotic therapy should be based on culture results. If no growth occurs, as is the case in a majority of blood cultures from cellulitis patients, 
then clinical acumen must be used to guide treatment changes $(1,3)$.

Limitations of the present study include the fact that it is retrospective. This resulted in many patients being excluded for various reasons, such as missing data from the chart, cultures not being performed, and patients receiving antibiotics before their admission. The limited number of patients admitted during the study period made it impractical to perform statistical calculations on much of the data. Cellulitis cultures were based on growth from blood samples. This limited culturepositive cellulitis to those with bacteremia. Thus, our cellulitis population may be biased towards more severe disease. Finally, due to the polymicrobial nature of abscesses and infected ulcers, as well as our study's limited numbers, we can not make any therapy recommendations for these infections.

\section{CONCLUSIONS}

Patients diagnosed with cellulitis should receive a single antibiotic directed toward the most common pathogens commonly identified in a particular hospital. Broad-spectrum antibiotic therapy should be reserved for patients who do not improve or have culture results that suggest additional antibiotics. A hospital-based algorithm, including the most likely organisms to cause certain types of soft tissue infections and the most likely antibiotics to cure them, is recommended. This algorithm should include the cost of each pill/dose used per antibiotic chosen especially in cases where a selection of antibiotics exists to cure the same infection.
DISCLOSURE: No funding was provided for the preparation of this manuscript. None of the authors have a financial interest in any of the products, devices or drugs mentioned in this manuscript.

\section{REFERENCES}

1. Eron L, Lipsky B, Low D, Nathawani D, Tice A, Volturo G. Managing skin and soft tissue infections: expert panel recommendations on key decision points. J Antimicrob Chemother 2003;53(Suppl 1):i3-i17.

2. Chiller K, Selkin B, Murakawa G. Skin microflora and bacterial infections of the skin. J Infec Dis 2001;6:170-4.

3. Dong S, Kelly K, Oland R, Holroyd B, Rowe B. ED Management of cellulitis: A review of five urban centers. Am J Emerg Med 2001;19:535-40.

4. DiNubile M, Lipsky B. Complicated infections of skin and skin structures: When the infection is more than skin deep. J Antimicrob Chemother 2004;53(Suppl 2):ii37-ii50.

5. Nichols R, Florman S. Clinical presentations of soft-tissue infections and surgical site infections. Clin Infect Dis 2001;33:S84-93.

6. Fluit A, Schmitz F, Verhoef J. Frequency of isolation of pathogens from bloodstream, nosocomial pneumonia, skin and soft tissue, and urinary tract infections occurring in European patients. Eur J Clin Microbiol Infect Dis 2001;20:188-91.

7. Gales A, Jones R, Pfaller M, Gordon K, Sader H; for the SENTRY Group. Two-year assessment of the pathogen frequency and antimicrobial resistance patterns among organisms isolated from skin and soft tissue infections in Latin American hospitals: Results from the SENTRY antimicrobial surveillance program, 1997-98. Int J Infec Dis 1999;4:75-84.

8. World Health Organization. International Statistical Classification of Diseases and Related Health Problems, 10th Revision. Geneva: World Health Organization, 2005. 